give them astronomical instead of musical lessons". Mr. Sidgwick also gives graphical descriptions of Herschel's labours as a telescope maker and shows how his careful application to this work enabled him to produce instruments of a quality far surpassing anything then available; so good, in fact, that the magnifying powers he was able to use were for a time doubted by his contemporaries.

But it is in William Herschel's prowess and assiduity as an observer that his greatest claim to fame lies ; and while it may be felt that Mr. Sidgwick gives more place to biographical details than to Herschel's astronomical work, nevertheless we do obtiin a real sense of the perpetual observing which Herschel carried out as well as of the devoted assistance rendered by his sister Caroline. As to Herschel's pioneering endeavours in the theoretical field, in which he drew on his own unique fund of observational material, it is here that the book is not quite so satisfactory, as is to be expected, perhaps, in one written to have so wide an appeal as is clearly Mr. Sidgwick's aim. All in all, however, this volume, written with style and imagination, gives a good portrait of one of astronomy's greatest figures. It is free from any gross errors and, with its short but useful bibliography, is to be recommended.

C. A. Ronan

\section{INTERNATIONAL CONGRESS OF ELECTRON MICROSCOPY}

Comptes Rendus du Premier Congrès International de Microscopie Électron que

Paris, 14-22 Septembre 1950. Mémoire hors série No. 1. Publié par la Société Française de Microscopie Théorique et Appliquée avee le concours du Centre National de la Recherche Scientifique. Pp. viii +768. (Paris : Éditions de la Revue d'Optiquo Théorique et Instrumentale, 1953.) 8000 francs.

HE First International Congress of Electron Microscopy, held in Paris in 1950, attracted such a great number of participants that the report of its proceedings constitutes in itself a survey of the whole subject of electron microscopy as it stood at that time. In a short review it is only possible to indicate its scope. Electron optical theory claims thirty-one papers, but the design and construction of the microscope itself only eight papers; there are twelve on electron diffraction. Metallurgical applications, in eighteen papers, include work on metal physics as well as on more immediately practical problems of both ferrous and non-ferrous metallurgy. Twenty contributions on chemical applications range from pigments and polymers to photographic emulsions and clays. Biological applications not unnaturally attracted most attention, with forty-four papers which dealt with specimen preparation techniques (fixation, drying, sectioning, replicas), on one hand, and on the other with the use of the electron microscope in almost every type of biological and medical problem (viruses, bacteria, cancer, nerve, muscle, blood cells, teeth).

In two respects the Congress report is more informative than the meeting itself: first, it was physically impossible to attend all the sessions, and now every paper is available in print ; and secondly, a large group of papers from Japan (twenty-four) which were read in title only are now printed in full.
Two complisints may be made against the report : it appears almost three years after the meeting, although the manuscripts should have been submitted before the meeting, and the price is high. The explanation in both cases probably goes back to the desire to include every contribution in full. In such a rapidly advancing subject as electron microscopy speed is possibly more important than comprehensiveness in publication.

It should also be mentioned that the Paris Congress was not the first in electron microscopy either de facto or de jure: the first meeting of the International Commission for Electron Microscopy to be held under the auspices of the International Council of Scientific Unions was held this year in London, and prior to the Paris meeting at least two conferences of an international character had taken plece, in Cambridge (1948) and in Delft (1949).

V. E. Cosslett

\section{USE OF DIMENSIONS IN PHYSICS}

Dimensional Methods and Their Applications

By Dr. C. M. Focken. Pp. viii +224 . (London : Edward Arnold and Co., 1953.) 30s. net.

I IKE most of the basic principles of science, the 1 subject of dimensions has grown up rather untidily; it is presented differently end with different conventions in almost every department. The appearance of this book, with its suggestions for standerdization and its careful consideration of meny of the difficulties involved, is therefore very welcome. If it reads in places somewhat like a tract, this is only because the author wishes to present every side of each problem and yet to make his own firm recommendation about which side to accept.

The subject is covered very well, with ample references and quotations from some of the more important papers. The sections on the dimensions of thermal and electrical and magnetic quantities will be found by most physicists to be extremely helpful.

In such a thorough treatment, it seems strange that the possibility of vector notation has not been considered. This could be very useful; for example, the dimensions of energy and of the moment of a force are both $\left(M L^{2} T^{-2}\right)$; but physically they are quite dissimilar, the former being a scalar and the latter a vector. If a distinction could be made, it would be possible to make use of the result that all terms of an equation should be either scalar or vector, as well as dimensionally similar.

One point with which physicists will be inclined to disagree is the author's rejection of the physical basis of the principle that the argument of a transcendental function (for example, $e^{x}$ ) should be dimensionless. This basis seems so reasonable that the reviewer, at any rate, will continue to make use of it when he has need.

The book is well bound; but the printing is rather displeasing. It appears to be reproduced from electric typewriting; but the spacing of the words and even of the letters is not up to good printing standards, and the right-hand edge of the type is often rather ragged. It is to be hoped that this method of printing books will not be copied until it is a great deal better. H. LIPSON 